\title{
Crioterapia na clínica veterinária: avaliação da praticabilidade, e efetividade em carcinoma espinocelular de felinos
}

Ronaldo LUCAS ${ }^{1}$

Carlos Eduardo LARSSON²

Correspondência para:

RONALDOLUCAS

R. Voluntários da Pátria 2570, apto 11

02402-000 - São Paulo-SP

ro_lucas@terra.com.br

Recebido para publicação: 08/04/2004 Aprovado para publicação: 24/10/2006

1 - Faculdade de Medicina Veterinária da Universidade de Santo Amaro, São

Paulo - SP

2 - Departamento de Clínica Médica da Faculdade de Medicina Veterinária

e Zootecnia da Universidade de São Paulo, São Paulo - SP

\section{Resumo}

Palavras-chave: Crioterapia.

Pela inexistência de trabalhos, enfocando a crioterapia em felinos domésticos, dispostos na bibliografia brasileira indexada, propôs-se avaliar a praticabilidade e efetividade da crioterapia no tratamento do carcinoma espinocelular em animais desta espécie. Cinqüenta animais foram submetidos ao procedimento, utilizando-se do nitrogênio líquido como criógeno (com auxílio de spray ou sondas). Observouse a completa remissão e cura em $80 \%$ das lesões, correspondendo a cura de $72 \%$ dos animais. A crioterapia revelou-se ainda um procedimento prático, seguro, e efetivo, nas condições da clínica veterinária paulistana.

\section{Introdução}

Os felinos podem apresentar diferentes tipos de neoplasias e, dentre estas, as mais comumente observadas são aquelas de origem cutânea. Podem-se encontrar neoplasias derivadas das diferentes camadas da epiderme; de glândulas anexas; dos folículos pilosos; de células responsáveis pela produção de melanina; de células mesenquimais ou do tecido linfóide e, finalmente, das células nervosas. As neoplasias cutâneas representam aproximadamente $30 \%$ daquelas dos felinos domésticos, na proporção de três blastomas malignos para um benigno. Dentre aquelas de origem epitelial, que perfazem $70 \%$ das neoplasias tegumentares arrolam-se: os carcinomas espinocelular (CEC) e carcinoma basocelular, o fibrossarcoma e o mastocitoma. ${ }^{1}$

Segundo Clarke $^{2}$, a freqüência de ocorrência do carcinoma espinocelular oscila entre nove e $25 \%$ de todas as neoplasias dos felinos. Sua causa não está totalmente esclarecida, porém, freqüentemente está associado aos efeitos deletérios causados pela exposição solar crônica. Geralmente, esta neoplasia é precedida por quadro de queratose actínica.

Em felinos, ocorre preferencialmente em animais idosos, geralmente aqueles de pelagem branca ou amarela, instala-se em áreas pouco recobertas por pêlos, como narina, pavilhões auriculares, pálpebras e em região temporal. As lesões (isoladas ou múltiplas) caracterizam-se, normalmente, por exulcerações ou úlceras recobertas ou não por crostas. ${ }^{1,2,3,4} \mathrm{O}$ diagnóstico diferencial é amplo e inclui a esporotricose, criptococose, micobacteriose atípica e o complexo granuloma eosinofílico, o diagnóstico preciso e definitivo é firmado pela histopatologia.

O CEC é uma enfermidade de difícil tratamento sendo citados na literatura tratamentos preventivos, pouco usuais, como a tatuagem das lesões e o uso de betacarotenos, que devem passar a ser utilizados quando do estabelecimento do diagnóstico de queratose actínica. Uma vez instalada a neoplasia, recomendam-se, ainda, protocolos de tratamento físico ou químicos, como crioterapia, radioterapia, hipertermia, quimioterapia e fotoquimioterapia. Afora 
estas, preconizam-se aquelas cruentas, que envolvem prévia anestesia, como a exérese cirúrgica radical e a quimioterapia intralesional com carboplatina. ${ }^{1,3,4,5}$ Os resultados dos tratamentos desta enfermidade revelam-se desanimadores, pois procedimentos como tatuagem das lesões, utilização de betacarotenos, quimioterapia e exérese cirúrgica radical têm demonstrado poucos resultados satisfatórios. Além do mais, nas condições brasileiras da medicina veterinária procedimentos como a radioterapia, fotoquimioterapia e hipertermia, não estão, ainda, disponíveis.

A crioterapia, também denominada de criocirurgia foi, inicialmente, conceituada, na década de 60 por Cooper ${ }^{6}$ como a aplicação do frio, com fins terapêuticos, visando a congelação dos tecidos biológicos, o que acarretaria inibição fisiológica ou destruição tecidual. Já, segundo Goldstein e Hess $^{7}$ seria o procedimento onde haveria a destruição seletiva de tecidos quando da alternância dos ciclos de congelamento e de descongelamento. $\mathrm{Na}$ década de 80 , Withrow $^{8}$ refere-se a tal modalidade de terapia como sendo o uso médico de baixas temperaturas, induzindo a morte celular. Trata-se de uma técnica muito difundida na medicina humana, mormente na especialidade dermatológica, onde há inúmeros relatos caracterizando sua aplicabilidade e indicações. ${ }^{5}$ Entretanto, na medicina veterinária, cotejando os relatos do emprego da crioterapia com aqueles da medicina humana pôde-se verificar que até meados deste século raros eram os trabalhos relativos ao emprego de agentes criógenos em lesões evidenciadas em animais. ${ }^{9}, 10$

Em 1955, Farrell tratou, pela primeira vez um caso de sarcóide eqüino com gelo $\operatorname{seco}^{11}$. Na Universidade de Washington, quando fixou, um fragmento de gelo seco, recoberto por bandagem, em um cão anestesiado para satisfazer sua curiosidade na efetividade do frio no controle da dor, obteve despigmentação pilar local. Como histologicamente os folículos continuavam intactos, Farrell ${ }^{12}$ propôs o termo: criocirurgia homocelular, que ficou, posteriormente, internacionalmente, conhecido por sua aplicabilidade na identificação de animais . Na década de 70 , veterinários ingleses e norte-americanos do afamado "The Animal Medical Center", de Nova Iorque, passam a publicar grande número de trabalhos, retratando a experiência obtida, em animais de guarda e companhia. ${ }^{11}$

Dentre as indicações da crioterapia, habitualmete dispostas na bibliografia, incluem-se o tratamento de distintos quadros, em especialidades como: estomatologia, oftalmologia, proctologia e dermatologia. ${ }^{13}$

Também, no contexto da medicina veterinária a crioterapia tem maiores possibilidades de emprego na dermatologia. Apesar das inúmeras referências dispostas na bibliografia, existe apenas um trabalho ${ }^{9}$ de tratamento de dermatoses animais com o uso da crioterapia na literatura nacional brasileira. $\mathrm{Na}$ bibliografia internacional há, finalmente, alguns que sintetizam informações ${ }^{14}$ de outros autores ou mesmo de serviços hospitalares, reunindo, neste último caso, um maior número de animais submetidos a tal modalidade de tratamento. ${ }^{15,16,17}$

A crioterapia pode ser uma opção terapêutica viável para o clínico veterinário. Baseado nestes fatos o presente trabalho objetivou avaliar o uso desta técnica no tratamento de carcinoma espinocelular em felinos, caracterizando-os quanto à identificação racial, etária, além de sua coloração. Propôs também observar a evolução dos casos tratados, assim como o eventual surgimento de intercorrências e/ou seqüelas, avaliando finalmente, a praticabilidade e efetividade do procedimento cotejando os resultados com aqueles dispostos nas bibliografias internacional e nacional.

\section{Material e Métodos}

Foram utilizados 50 animais da espécie felina, atendidos no período de 1992 a 2001, no Serviço de Dermatologia do Departamento de Clínica Médica e do 
Hospital Veterinário da Faculdade de Medicina Veterinária e Zootecnia da Universidade de São Paulo.

Após a realização de anamnese pormenorizada, os animais eram submetidos à exame físico, com ênfase no exame dermatológico, e a exames complementares, sempre incluindo a prévia biópsia para exame histopatológico de pele. Após confirmação do diagnóstico presuntivo de CEC, indicou-se o procedimento crioterápico, utilizando o aparelho CRY-AC- $3^{1}$. Para tanto os animais foram submetidos à anestesia geral.

A técnica utilizada foi a da aplicação de nitrogênio líquido, com auxílio de spray ou cone. O tempo de congelamento variou de 90 a 240 segundos, utilizando-se margem de segurança perilesional de 5 a $15 \mathrm{~mm}$ (figura 2). O descongelamento se deu naturalmente, em temperatura ambiente. Os animais, submetidos ao tratamento, sofreram reavaliação periódica, em retornos quinzenais. A neoplasia foi considerada controlada nos felinos onde as lesões tegumentares iniciais foram substituidas por lesões cicatriciais, sendo então indicada a alta clínica. Avaliaram-se ainda, os dados referentes a intercorrências (alterações transitórias) e seqüelas (alterações permanentes). Os animais submetidos ao tratamento foram acompanhados por período oscilando entre quatro e 50 meses.

\section{Resultados}

Realizou-se a crioterapia em 50 felinos, sendo 32 fêmeas e 18 machos, com faixa etária situada entre 36 e 250 meses de vida (60\% com idade entre 97 e 144 meses). Pôde-se caracterizar $47(94,0 \%)$ destes espécimes como animais sem uma perfeita definição racial (SRD), sendo que apenas 3 $(6,0 \%)$ eram animais de raça definida (CRD).

Em termos de decurso evolutivo a evolução do quadro oscilava entre 1 e 48 meses. Dos 50 animais, 32 (64\%), já haviam sido submetidos à outras modalidades terapêuticas, como exérese cirúrgica, curetagem e corticoideterapia, sem resultados satisfatórios.

Das 100 lesões tegumentares detectadas e tratadas, verificou-se que mais freqüentes foram aquelas agrupadas dentre as "perdas e reparações teciduais" - úlceras $(52-52 \%)$, erosões $(21-21 \%)$ e crostas (1717\%), além de "formações sólidas - nódulos (10-10\%). Quanto a cor do pelame eram os gatos totalmente brancos [Fig. 1](32-64\%), bicolores $(10-20 \%)$, tricolores $(5-10 \%) \mathrm{e}$ amarelos (3-6\%). Todas as lesões assestavamse em regiões não-pigmentadas. $\mathrm{O}$ tamanho das lesões criotratadas variou de menos de um centímetro até nove centímetros de

Tabela 1 - Local de assestamento de 100 lesões em 50 felinos com carcinoma espinocelular submetidos à crioterapia. Serviço de Dermatologia da FMVZ/USP (1992 a 2001). São Paulo, 2004

\begin{tabular}{lcc}
\hline Região anatômica & Número total por região & $\begin{array}{c}\text { Número } \\
\text { parcial }\end{array}$ \\
\hline CEFÁLICA & 94 & 40 \\
Narina (plano e espelho nasal) & & 31 \\
Pavilhão auricular & 1 \\
Poro acústico & 12 \\
Periocular/Palpebral & & 2 \\
Labial & & 2 \\
Mento & & 6 \\
Temporal & 4 & \\
CERVICAL & 2 & \\
ABDOMINAL & 100 & \\
Total & & \\
\hline
\end{tabular}


diâmetro, $72 \%$ dos animais apresentavam lesões com diâmetros oscilando entre menos de um centímetro e de até três centímetros de diâmetro. Apenas 14\% deles apresentavam lesões de tamanho superior a cinco centímetros de diâmetro.

As lesões, na sua totalidade, eram do tipo localizada. Na Tabela 1 arrolam-se os locais de instalação das lesões cutâneas elementares identificadas nos animais tratados.

Obteve-se a involução lesional e cura (Figuras 3 e 4) de $80 \%$ das lesões criotratadas com a conseqüente resolução do quadro mórbido em $72 \%$ dos felinos sumetidos ao procedimento.

Não se evidenciou nenhum tipo de complicação ou seqüela em 37 dos animais $(74,0 \%)$ tratados. Nos outros $13(26,0 \%)$ animais as complicações mais observadas foram: perda tecidual, esternutação e ceratoconjuntivite seca observados no póscrioterapia imediato ou mediato.

\section{Discussão}

Os espécimes selecionados para serem submetidos ao procedimento crioterápico eram, na sua grande maioria, felinos sem uma perfeita definição racial (94\%) e fêmeas (64\%). Os animais idosos também representavam a maioria $(60 \%)$ dos casos tratados. São justamente os animais de faixa etária tardia ou com condições orgânicas (debilitação etária) em que o procedimento crioterápico é mais indicado, quando da escolha da forma de tratamento, por exigir, pelo menos, uma anestesia de breve duração.

A observação de que todos os animais apresentavam lesões em regiões corpóreas recobertas por pêlos de coloração branca confirma as observações de diferentes autores, sobre a maior incidência desta enfermidade decorrente da exposição crônica à radiação solar, em animais de pelagem clara e com idade avançada. . $^{1,23,3,18,19}$

Quanto à localização das lesões, estas se localizavam, na sua grande maioria, em região cefálica (Figuras 1, 2, 3 e 4), novamente corroborando as observações de vários outros autores. ${ }^{1,2,3,5,12}$ Ressalte-se ainda, que segundo Scott, Miller e Griffin ${ }^{4}$, é muito pouco freqüente o assestamento desta enfermidade na região ungueal, tal assertiva pôde ser confirmada pela não observação de neoplasias de localização ungueal nos 50 felinos submetidos ao tratamento.

Das lesões de felinos submetidas à crioterapia as perdas e reparações teciduais (erosões, úlceras e crostas) foram as mais freqüentemente identificadas. Tais tipos lesionais são exatamente aqueles com maiores indicações de submissão à crioterapia, segundo vários autores. ${ }^{1,2,3,4,11}$

Das 100 lesões tratadas, no presente trabalho, $94 \%$ destas se localizavam na região cefálica, sendo que $40 \%$ delas se situavam nas narinas, 31\% nos pavilhões auriculares e, finalmente, $12 \%$ nas pálpebras. Houve, também, a evidenciação de lesões em outras partes do tegumento, como nas regiões cervical e abdominal. Também, Clarke ${ }^{2}$, procedeu a crioterapia em 198 lesões de gatos distribuídas da seguinte maneira: 55\% em narinas, $30 \%$ em pavilhões auriculares e $15 \%$ em pálpebras, ou seja, 100\% delas se localizavam em região cefálica.

Deve-se ainda ressaltar as indicações referidas por alguns autores $\mathrm{s}^{6,10,12,15,16,20,21,22,23}$, sobre o uso da crioterapia em áreas em que suturas são contra-indicadas bem como naquelas onde o acesso cirúrgico convencional se torna difícil pelas próprias características anatômicas das região, como a face e, mais especificamente, narina e pálpebras. Os resultados obtidos vieram a confirmar o acerto da indicação face ao êxito evidenciado no tratamento das lesões cefálicas, pois obteve-se remissão em 80 de 100 lesões criotratadas, comprovando-se, cabalmente, a indicação e a efetividade do procedimento quando aplicado em tais regiões. As intercorrências e seqüelas (perda tecidual, esternutação e ceratoconjuntivite seca) ocorreram em 26\% dos animais submetidos ao tratamento, sendo estas as já esperadas e, também, observadas por 


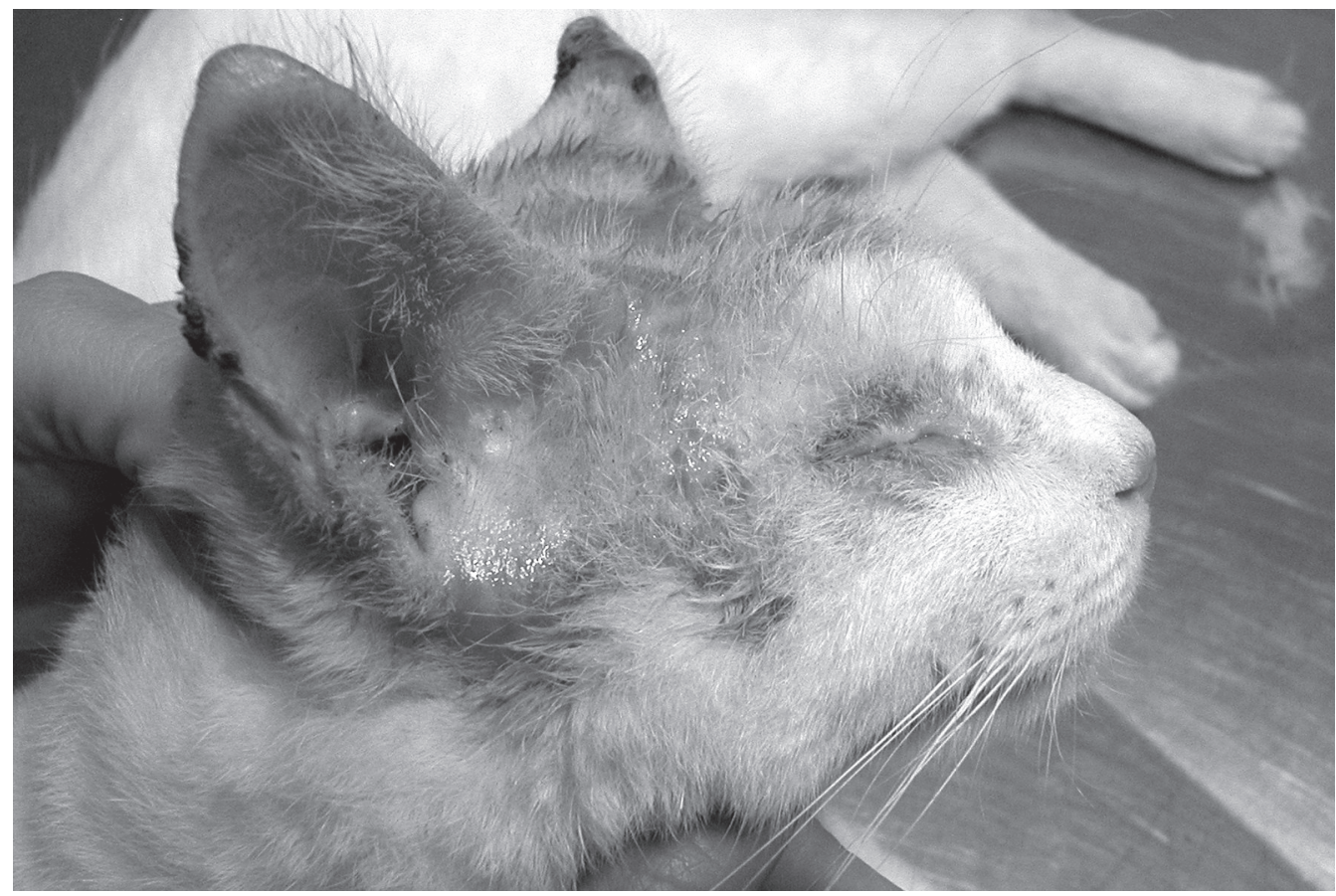

Figura 1 - Exulcerações e úlceras em região periauricular, periocular e orelhas de felino, macho, 7 anos, sem raça definida de pelame branco. Caso de carcinoma espinocelular

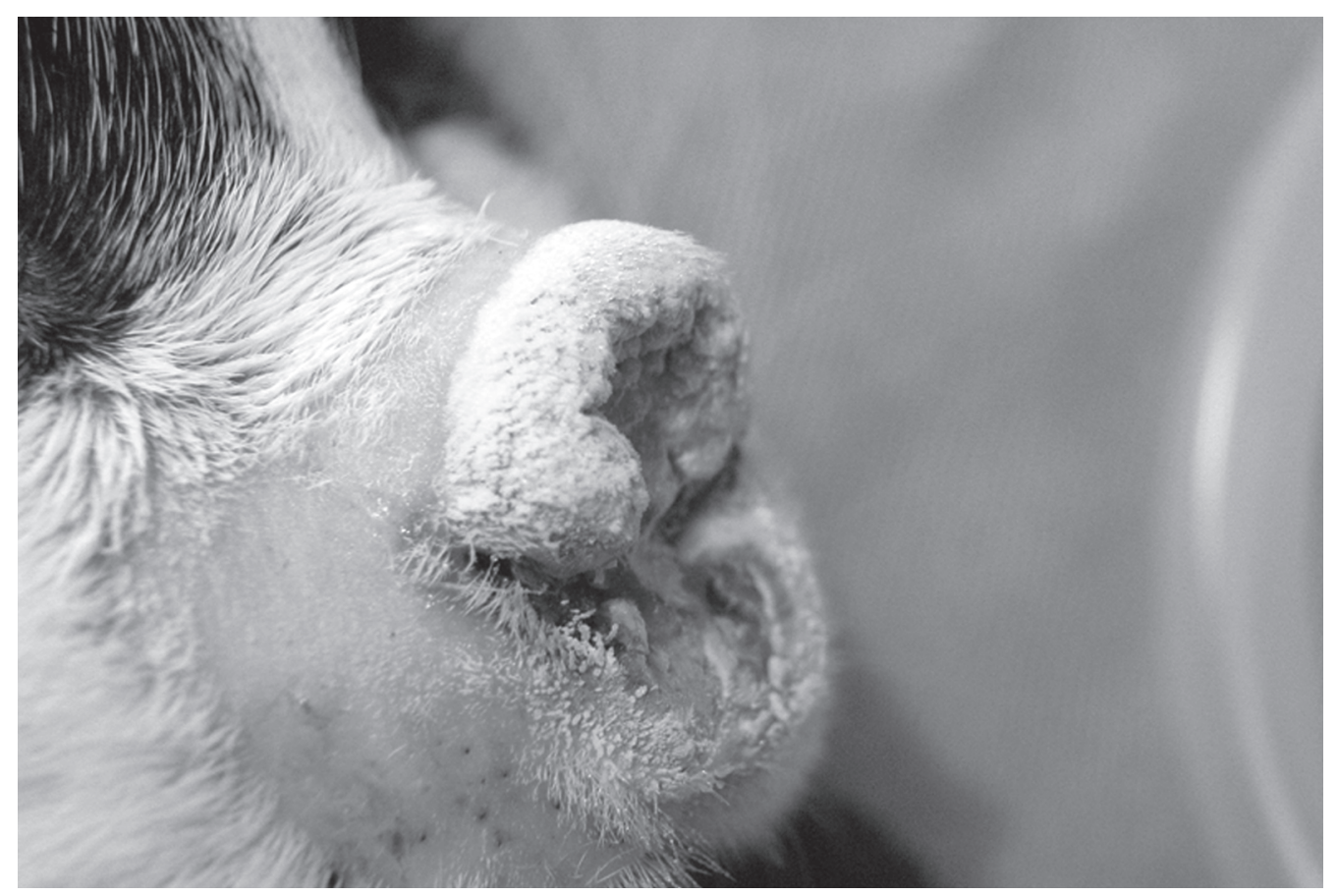

Figura 2 - Narina de felino com carcinoma espinocelular congelada, após aplicação de nitrogênio líquido 

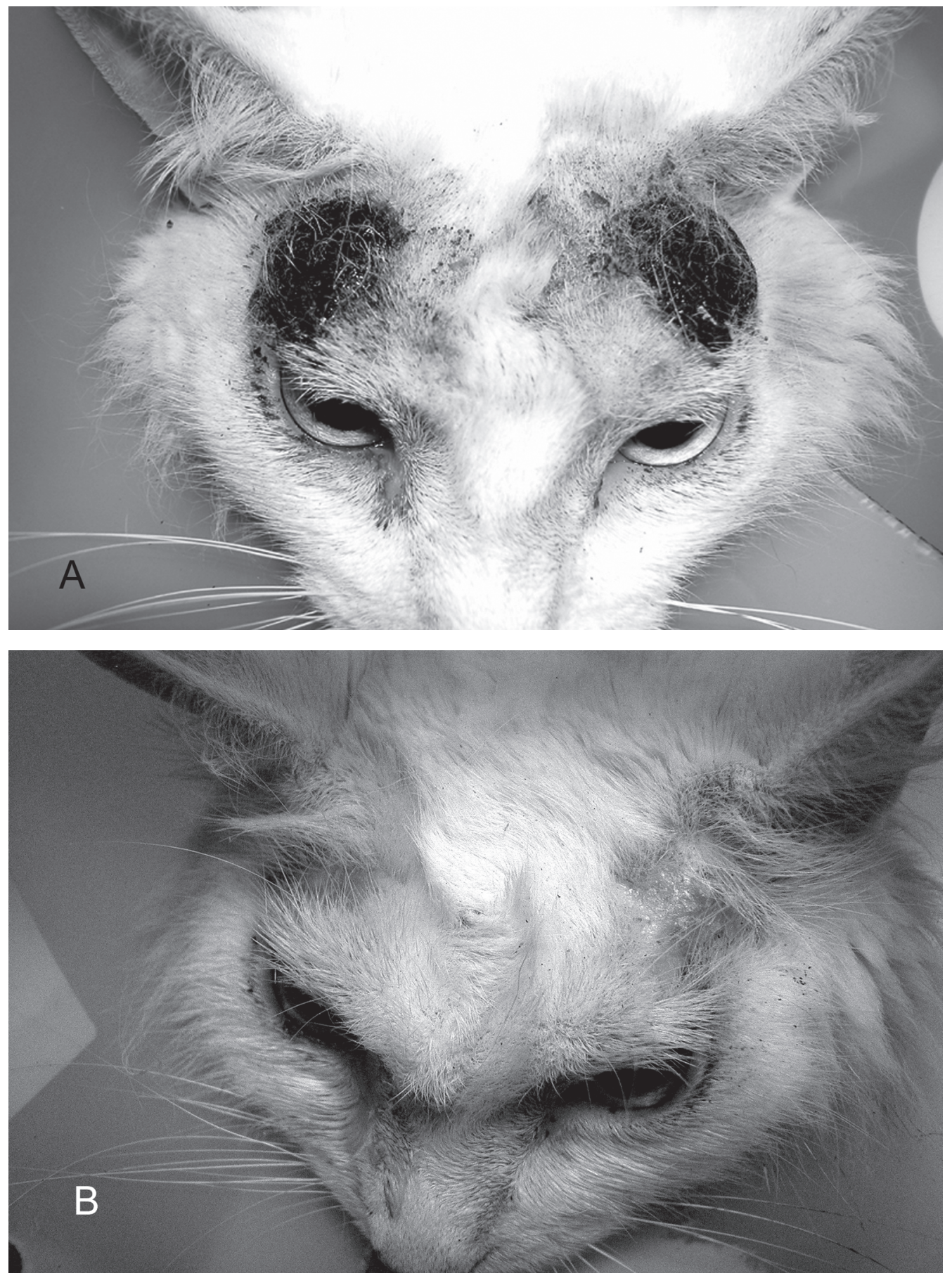

Figura 3 - A) Felino, fêmea, sem raça definida de 7 anos de idade com crostas em região temporal, uma semana após a crioterapia, em carcinoma espinocelular. B) Mesmo felino após cicatrização da lesão 

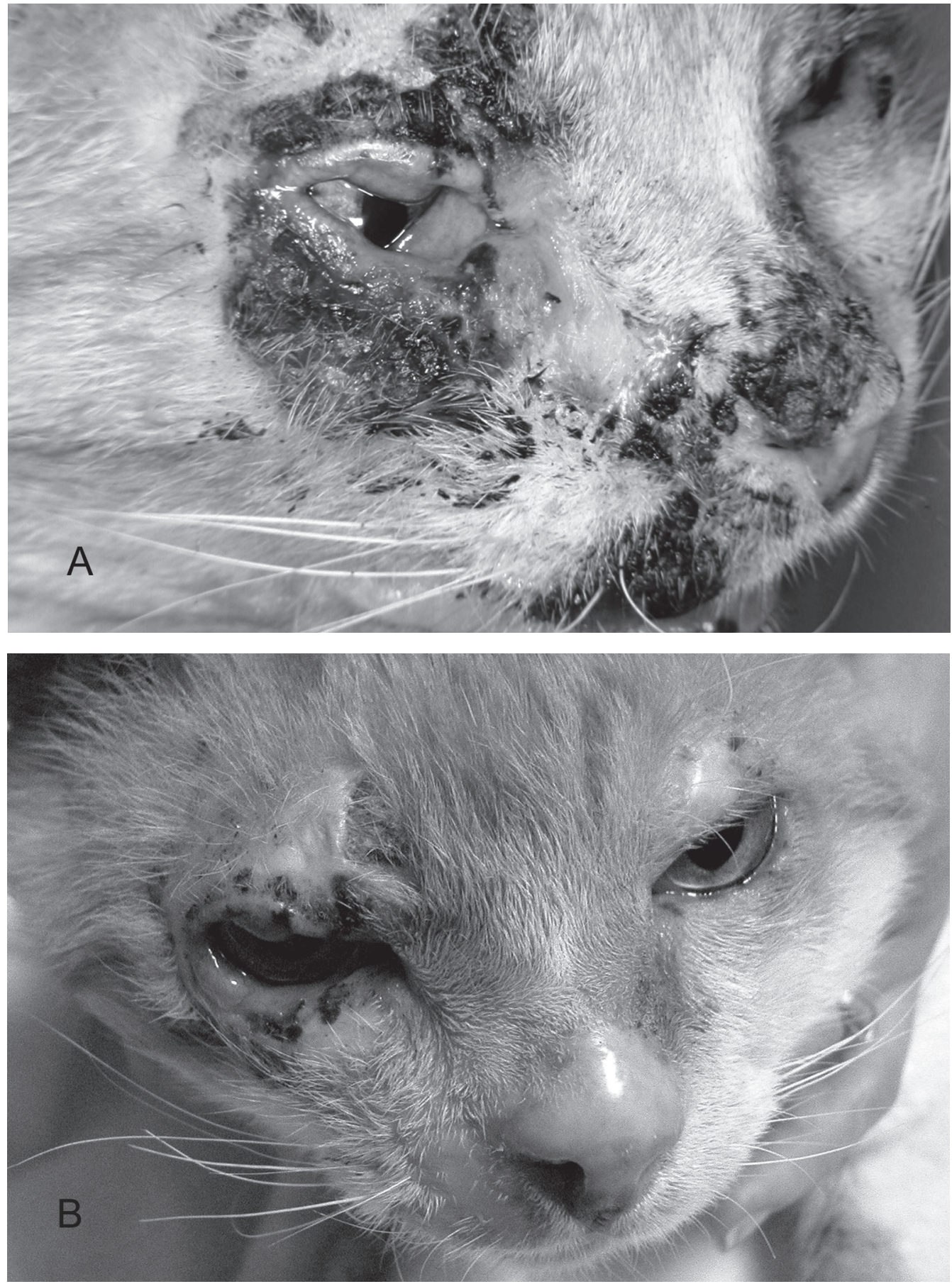

Figura 4 - A) Felino,macho, sem raça definida, bicolor de 9 anos de idade com carcinoma espinocelular em face, acometendo narina, lábio, região temporal e periocular .B) Mesmo felino após cicatrização das lesões que foram submetidas ao procedimento crioterápico 
diferentes autores. ${ }^{1,2,3,24,25}$

A crioterapia foi empregada em lesões cutâneas elementares com dimensões muito variadas. Poucos são os autores que indicam o procedimento em lesões muito amplas sendo, também, raros aqueles que se preocuparam em estabelecer a factibilidade e o êxito correlacionando-os a aspectos morfométricos da área lesada tratada. Krahwinkel Jr., Merkley e Howard ${ }^{15}$ recomendam a crioterapia em lesões de dimensões variadas, todavia se restringe com maior ênfase àquelas de até um centímetro. Withrow, Greiner e Liska ${ }^{17}$ propõe o emprego do criógeno em lesões de até 2,5 centímetros. Finalmente Farris, Fraunfelder e Frith ${ }^{20}$ recomendaram-na em neoplasias perianais de até sete centímetros de diâmetro. No presente trabalho empregou-se o nitrogênio líquido em lesões de até nove centímetros de diâmetro, sendo que a maior parte das lesões submetidas ao procedimento eram aquelas de dimensões de até três centímetros de diâmetro.

Podokonjack ${ }^{10}$ relatou um índice relativo de sucesso de $75 \%$ em casos de carcinoma espinocelular criotratados de cães. Entre os 50 felinos, ora tratados, se obteve $72 \%$ de êxito. Em termos comparativos, Clarke $^{2}$, observou $83,0 \%$ de sucesso em tratamentos de 102 casos.

As diferenças observadas, no que tange aos percentuais de sucesso, quando da comparação com trabalhos congêneres podem, quiçá, ser explicadas pelo emprego do protocolo em diferentes estádios evolutivos, em distintas localizações e em variados tamanhos de lesão. Nos Serviços de Dermatologia e de Cirurgia do Hospital Veterinário da Faculdade de Medicina Veterinária e Zootecnia da Universidade de São Paulo, não se adota nenhum protocolo em casos ditos avançados de carcinoma epidermóide, sediados na região nasal, a não ser o crioterápico. Esta adoção, nesses casos extremos, evita a dolorosa e desalentadora recomendação, pura e simples, da eutanásia. Portanto, o percentual de $72 \%$ de sucesso no tratamento de pacientes felinos acometidos por este blastoma pode ser considerado até como muito auspicioso.

A crioterapia foi considerada bem sucedida, quando se constatava a plena involução das lesões tegumentares iniciais e a substituição destas por lesões cicatriciais. Este mesmo critério foi usado para a avaliação do sucesso do procedimento empregado em trabalhos similares. ${ }^{2,914,16,20,21,23}$ Não se realizaram controles pós-tratamento, através de exames histopatológicos, pois exames adicionais, realizados em laboratório privado, gerariam gastos adicionais de parte dos proprietários dos animais, pelo fato de ser necessário uma nova anestesia geral, habitualmente recusada pelos donos, tanto pelo custo como pelos potenciais riscos anestésicos, principalmente dos animais idosos, e, ainda, pela suposta alteração do excelente aspecto cicatricial que poderia advir. Os riscos anestésicos contrapõem uma das maiores vantagens apontadas no tratamento, com a utilização de criógenos, que é justamente a redução do tempo de anestesia, pelo menor tempo dispendido no procedimento ou até pela possível realização deste sem o emprego de anestesia geral.

Assim, em se analisando todo o grupo de felinos submetidos ao tratamento, segundo o número de lesões criotratadas, pôde-se constatar que na grande maioria (100 lesões $80 \%$ de cura), alcançaram-se resultados excelentes com plena e total remissão do quadro neoplásico em $72 \%$ dos animais submetidos ao tratamento. Frente a tais resultados e, ainda, levando-se em conta que a crioterapia era a única opção terapêutica possível, pode-se, finalmente, afirmar que estes animais foram bastante beneficiados e, provavelmente, salvos pelo procedimento, o que é obviamente, o principal desiderato do clínico veterinário. Seguramente, mesmo nos animais em que o tratamento não surtiu pleno êxito, obteve-se o prolongamento de vida, com qualidade, nesta enfermidade de prognóstico reservado.

\section{Conclusões}

1.Os felinos portadores de carcinoma 
espinocelular eram representados na sua maioria por animais idosos, fêmeas, com quadro de evolução crônica e que na sua totalidade apresentavam lesões, em áreas não pigmentadas da região cefálica e com densidade reduzida de pêlos.

2.Os resultados finais em termos de involução plena e desaparecimento das lesões com a conseqüente resolução do quadro mórbido (72\%), além do pequeno número de interconrrências e seqüelas observadas, retratam o êxito cabal do procedimento, prático e efetivo, nas condições da clínica veterinária paulista.

3.A crioterapia pôde ser empregada em lesões de prognóstico bem reservado, em animais de distintas faixas etárias, consistindo em técnica alternativa exeqüível, prática e efetiva, evitando a desalentadora eutanásia.

\section{Agradecimentos}

Os autores agradecem aos professores Eugênio Pimentel e Nílceo Michalany, pela colaboração no desenvolvimento do trabalho.

\title{
Cryotherapy in veterinary clinic: evaluation of its practicability and effectiveness in feline squamous cell carcinoma
}

\begin{abstract}
Based on the absence of detailed and ample papers disposed at the literature, focusing cryosurgery in domestic cats, we aim with this work, to evaluate the practicability and effectiveness of this method in squamous cell carcinoma. We submitted 50 cats to cryosurgery, using liquid nitrogen as a cryogen (by spray or probe equipment). It was observed a complete remission and cure in $80 \%$ of lesions, corresponding to a cure rate of $72 \%$. The cryosurgery was considered a practical, safe and effective method to be performed at the small animals veterinary clinic condition at the city of São Paulo, Brazil.
\end{abstract}

Key-words:

Cryotherapy. Carcinoma. Feline.

\section{Referências}

1 DESLIE, F.; DEVAUCHELLE, P. Skin tumours. In: GUAGUÈRE, E.; PASCAL, P. A practical guide to Feline Dermatology. [s. I.]: Merial, 2000. p. 15.1-15.14.

2 CLARKE, R. E. Cryosurgical treatment of feline cutaneous squamous cell carcinoma. Australian Veterinary Practice, v. 21, n. 3, p. 148-153, 1991.

3 GRIFFIN, C. E.; KWOCHKA, K. W.; MACDONALD, J. M. Current veterinary dermatology. Missouri: Mosby, 1993. p. 187.

4 SCOTT, D. W.; MILLER Jr., W. H.; GRIFFIN, C. G. Small animal dermatology. Philadelphia: Saunders, 2001. p. 1528.

5 MARQUES, L. A. C. Criocirurgia: nossa experiência. Rio de Janeiro, 1989. 112 p. Dissertação (Mestrado) Pontifícia Universidade Católica do Rio de Janeiro, Rio de Janeiro, 1989. .

6 COOPER, I. S. Criogenic surgery: a new method of destruction or extirpation of benign and malignant tissue. New England Journal of Medicine, v. 268, p. 743, 1963.
7 GOLDSTEIN, R. S.; HESS, P. W. Cryosurgical treatment of cancer. Veterinary Clinics of North America, v. 7, n. 1, p. 51-64, 1977.

8 WITHROW, S. J. General principles of cryosurgical technique. Veterinary Clinics of North America: Small Animal Practice, v. 10, n. 4, p. 779-786, 1980.

9 LUCAS, R.; LARSSON, C. E. Crioterapia na clinica veterinária: avaliação da praticidade, exequibilidade e efetividade em dermatopatias de caninos. Anais Brasileiros de Dermatologia, v. 77, n. 3, p. 291-299, 2002

10 PODKONJAK, K. R. Veterinary cryotherapy. 1. a comprehensive look at uses, principles, and successes. Veterinary Medicine: Small Animal Clinician, v. 77, p. 51-64, 1982a.

11 GREINER, T. P.; LISKA, W. D.; WITHROW, S. J. Cryosurgery. Veterinary Clinics of North America, v. 5, n. 3, p. 565-581, 1975.

12 FARREL, R. K. Simplified Cryotherapy. Veterinary Medicine: Small Animal Clinician, v. 73, n. 11, p. 13771384, 1978.

13 PIMENTEL, E. R. A. Controle histologico pelo método micrográfico de Mohs em carcinoma 
basocelular tratado pela criocirurgia com nitrogênio líquido. 1997. Tese (Doutorado) - Faculdade de Medicina, Universidade de São Paulo, São Paulo, 1997.

14 LISKA, W. D.; GREINER, T. P.; WITHROW, S. Cryosurgery in the treatment of perianal fistulae. Veterinary Clinics of North America, v. 5, n. 3, p. 449457, 1975.

15 KRAHWINKEL, Jr., D. J.; MERKLEY, D. F.; HOWARD, D. R. Cryosurgical treatment of cancerous and noncancerous diseases of dogs, horses, and cats. Journal of the American Veterinary Medical Association, v. 16, p. 201-207, 1976.

16 NORSWORTHY, G. D.; MILLER, D. C.; RADICKE, L. E.; LIMMER, B. L. Cryosurgery in small animal practice. Canine Practice, v. 4, n. 4, p. 18-22, 1977.

17 WITHROW, S. J.; GREINER, T. R.; LISKA, W. D. Cryosurgery: veterinary considerations. Journal of the American Animal Hospital Association, v. 11, p. 27182, 1975.

18 LUCAS, R. Diagnóstico diferencial do prurido In: SOUZA, H. J. M. Coletâneas em medicina e cirurgia felina. Rio de Janeiro: L.F. livros, 2003. p. 115-153.

19 MULLER, G. H.; KIRK, R. W.; SCOTT, D. W. Small animal dermatology. Philadelphia: Saunders, 1989. 809 p.

20 FARRIS, H. E.; FRAUNFELDER, F. T.; FRITH, C. H. Cryosurgical treatment of canine perianal gland adenomas. Canine Practice, august, p. 34-37, 1976.

21 LISKA, W. D.; WITHROW, S. Cryosurgical treatment of perianal gland adenomas in the dog. Journal of the American Animal Hospital Association. v. 14 , p. $457-463,1978$

22 PODKONJAK, K. R. Veterinary cryotherapy. 2. a comprehensive look at uses, principles, and successes. Veterinary Medicine: Small Animal Clinician, v. 77, p. 183-290, 1982b.

23 ROBERTS, S. M.; SEVERIN, G. A.; LAVACH, J. D. Prevalence and treatment of palpebral neoplasms in the dogs: 200 cases (1975-1983). . Journal of the American Veterinary Medical Association, v. 189, n. 10, p. 135-59, 1986.

24 FRETZ, P. B.; HOLMBERG, D. L. Sequelae to cryosurgery. Veterinary Clinics of North America: Small Animal Practice, v. 10, n. 4, p. 869-875, 1980.

25 HOLMBERG, L. The sequelae of cryosurgery on the pálpebra of dogs. Canadian Veterinary Journal, v. 20, n. 2, p. 57, 1978. (Abstract). 